\title{
Vulneración al derecho a una justa remuneración a los trabajadores del sector privado en Ecuador
}

Violation of the right to fair remuneration for private sector workers in Ecuador

\author{
Manacés Esaud Gaspar-Santos \\ uq.manacesgaspar@uniandes.edu.ec \\ Universidad Regional Autónoma de los Andes, Quevedo \\ Ecuador \\ https://orcid.org/0000-0003-4929-4495 \\ Klever Javier Cruz-Gálvez \\ dq.klevericg48@uniandes.edu.ec \\ Universidad Regional Autónoma de los Andes, Quevedo \\ Ecuador \\ https://orcid.org/0000-0002-7189-4625 \\ Lady Sadith Marín-Vilela \\ dq.ladysmv00@uniandes.edu.ec \\ Universidad Regional Autónoma de los Andes, Quevedo \\ Ecuador \\ https://orcid.org/0000-0002-8280-3872 \\ Kahyner Yuleydi Mendoza-Arce \\ dq.kahyneryma61@uniandes.edu.ec \\ Universidad Regional Autónoma de los Andes, Quevedo \\ Ecuador \\ https://orcid.org/0000-0003-3350-0741
}

Recepción: 15 de septiembre 2021

Revisado: 25 octubre 2021

Aprobación: 15 de noviembre 2021

Publicación: 01 de diciembre 2021 


\section{Estimado Editor (a):}

La vulneración del derecho a una justa remuneración no es un problema actual, es un inconveniente que ha sobrevivido con el pasar de los años desde la antigüedad, ya que, por lo general el hombre siempre ha sido explotado por el hombre, sobre todo en la época de la esclavitud fueron tantas y constantes las luchas por los derechos que actualmente se conocen como derechos laborales. Se debe de tomar en cuenta lo que menciona la (Organización Internacional del Trabajo, 2021), la OIT ha realizado aportes importantes al mundo del trabajo desde sus primeros días. La primera Conferencia Internacional del Trabajo en Washington en octubre de 1919 adoptó seis Convenios Internacionales del Trabajo, que se referían a las horas de trabajo en la industria, desempleo, protección de la maternidad, trabajo nocturno de las mujeres, edad mínima y trabajo nocturno de los menores en la industria, mismos que en cumplimiento del principio Pacta Sunt Servanda el Ecuador debe de adoptar los mecanismos necesarios para cumplir con estos tratados, y en este caso, aquel mecanismo es la inspectoría de trabajo, quien tiene como atribución controlar el cumplimiento de las disposiciones de la constitución y del código de trabajo, razón por la cual el análisis jurídico se enfoca en la vulneración al derecho a una justa remuneración a las personas que laboran en las empresas privadas que según las encuestas realizadas es donde más se vive estos abusos debido a la falta de control por parte de los inspectores de trabajo.

En este sentido, las vulneraciones a la estabilidad laboral, es una de las preocupaciones que mantienen hoy en día los trabajadores en sus puestos de trabajo, ya que la garantía es existente en la constitución, leyes, tratados internacionales, pero en la práctica, los procesos son largos y desgastantes, donde en la mayoría de las ocasiones las empresas no pagan lo correspondiente y los trabajadores aceptan acuerdos aceptables con la finalidad de no desgastarse en un proceso tedioso.

Así mismo, el artículo 328 de la Constitución de la República del Ecuador establece el derecho, a una remuneración justa, con un salario digno, que cubra aquellas necesidades básicas de todos los trabajadores, de su familia, el estado es quien fija y revisa anualmente el salario básico que establece la ley, el pago de estas 
remuneraciones, se deberán de otorgar en el plazo que se acordó en el contrato y no podrá ser descontado, además, el trabajador del sector privado tiene derecho de participar en las utilidades líquidas de la empresa, y por otro lado, establece con dureza que todo fraude o falsedad en la declaración de estas utilidades que perjudiquen estos derechos serán sancionados por la ley.

Además, la constitución contempla todos los derechos a los que todas las personas sin importar su condición económica, política o social, tienen derecho de acceder, pero son derechos que son vulnerados a gran escala, ya que, por motivos de alto índice de desempleo que existe en el Ecuador, que según datos oficiales del (INEC, 2020) realizados el 20 de diciembre del año 2020, el desempleo llego al $5.0 \%$ por tal motivo los trabajadores prefieren tener un trabajo en el que no se respeten sus derechos a que estar desempleados, pero esta historia sería completamente, si la institución encargada de cumplir con el control del cumplimiento de los derechos de los trabajadores, si realmente se hicieran estos controles, tal vez los derechos de los trabajadores no serían tan pisoteados, puesto que estos controles son muy escasos, rara vez un inspector de trabajo llega a las empresas privadas, llega a ejercer su atribución de control, para esto el trabajador debe de ir a informar o a denunciar ante el inspector de trabajo, lo que supone grandes riesgos para ese trabajador al perder su trabajo.

Pese a que, el código de trabajo en el artículo 545, establece estas atribuciones, que desde nuestra forma de pensar son más obligaciones que tienen los inspectores de trabajo como lo establece el numeral 1.- Cuidar que en todos los centros de trabajo se observe las disposiciones sobre la seguridad e higiene, pero si se le da una interpretación tomando en cuenta la realidad que se vive a raíz de la pandemia, también están incluidos las medidas de prevención del COVID-19, mismos que en algunos establecimientos no se cumplen, en el numeral 2.- cuidar de que en todas las relaciones provenientes del trabajo se respeten los derechos y que se cumplan con obligaciones que la ley impone a trabajadores, dentro de este artículo se establece que se tiene que controlar que se cumplan con los derechos y obligaciones de empleadores y trabajadores, las obligaciones del empleador se encuentran detalladas 
en el artículo 42 del código de trabajo, en que por no hacer muy extenso este análisis, solo se observará el numeral 1.- en el que establece que el empleador está obligado a pagar las cantidades que correspondan al trabajador, en los términos del contrato y de acuerdo con las disposiciones de este Código; es decir; toda actuación contraria a este artículo por la parte empleadora vulnera los derechos de los trabajadores. En el numeral 3.- establece como atribuciones de los inspectores de trabajo que debe de realizar visitas como lo establece el artículo 542, es decir visitar todas las empresas privadas para controlar el cumplimiento de los derechos, lo que en la realidad NO sucede, el numeral 4.- Debe de verificar mediante la revisión de documentos, y registro de las empresas, la interrogación al personal de los establecimientos sin presencia de testigos, etc., del cumplimiento de las disposiciones legales y reglamentarias referentes al trabajo, y hacer constar sus observaciones en los informes que eleven a sus respectivos superiores jerárquicos; lo que en la realidad que viven los trabajadores NO sucede, por lo consiguiente el numeral 5 establece que debe de conceder o negar el visto bueno en las solicitudes de despido de los trabajadores o de separación de éstos, $\mathrm{y}$, de acuerdo con las prescripciones pertinentes de este Código; en el numeral 6. Intervenir en las comisiones de control; en el numeral 7. Imponer multas de acuerdo con las normas de este Código, si se efectuara el respectivo control, entonces si pudieran imponer multas, pero como no se realiza muy a menudo, entonces no es posible imponer multas a los empleadores.

En cuanto al derecho a una justa remuneración, esto se ve vulnerado notablemente por algunas empresas ya que en su mayoría solo pagan el Salario Básico Unificado del Trabajador; sin importar el nivel académico de la persona, lo máximo que pagan es el Salario Básico, por motivos legales, no se puede divulgar el nombre de la empresa en la que se basa este proyecto de investigación, y además para proteger a los trabajadores de la empresa y de este modo no ponerlos en una situación de vulnerabilidad, pero, dentro la empresa anónima el administrador de la empresa, el asistente de ventas, el personal de carga, el chofer, ganan lo mismo ya que ninguno de ellos tiene un área de trabajo definido ya que, simplemente tienen que cumplir con todas las disposiciones de su empleador, cumpliendo con un horario de trabajo de 
lunes a sábado, de 8:00 horas a las 19:00 horas, no reciben el pago de los días sábados, ni de la correspondiente horas suplementarias y extraordinarias a las que el trabajador tiene derecho, no reciben Décimo tercero, Décimo cuarto, vacaciones, afiliación al IESS, utilidades, en fin lo único que reciben es el SBU, y muchas y constantes atropellos a sus derechos, y la pregunta está en ¿Dónde está el inspector de trabajo? como atribuciones tiene que realizar visitar y revisar documentos para cerciorarse del cumplimiento de todos sus derechos, si realmente se realizaran estos controles la vulneración de derechos no sería tan grotesca.

Por lo tanto, la vulneración al derecho a una justa remuneración debido a la falta de control por parte de la inspectoría de trabajo, es un problema que ha venido siendo combatido durante muchos años, en luchas constantes por los derechos de los trabajadores, pero con la pandemia COVID-19 estos han sido objeto de vulneración constante, no solo por parte de los empleadores sino también por parte de la Asamblea Nacional, ya que, con la finalidad de combatir la crisis económica ha dejado desamparados a los trabajadores favoreciendo a los empleadores, a los grandes empresarios, y por otro lado la Corte Constitucional del Ecuador no se ha manifestado al respecto de la Ley Orgánica de apoyo humanitario, pese a que es el máximo órgano de control e interpretación constitucional.

\section{FINANCIAMIENTO}

No monetario.

\section{AGRADECIMIENTO}

A la Universidad Regional Autónoma de los Andes, Quevedo, por motivar el desarrollo de la Investigación.

\section{REFERENCIAS CONSULTADAS}

Asamblea Nacional Constituyente de la República del Ecuador, (2008). Constitución de la República del Ecuador. [Constitution of the Republic of Ecuador]. Montecristi. Registro Oficial 449 de 20-oct-2008. Recuperado de https://n9.cl/sia 
Asamblea Nacional de la República del Ecuador (2005). Código del Trabajo, Ecuador. [Labor Code, Ecuado]. Registro Oficial Número 167. 16 de diciembre de 2005. Última reforma 20 de abril de 2015. Recuperado de: https://n9.cl/652cf

Instituto Nacional de Estadística y Censos (2021) Empleo e indicadores laborales. [Employ labor indicators]. Recuperado de: https://n9.cl/hd1t

Instituto Nacional de Estadística y Censos (2020). Censo. [Census] Recuperado de: https://n9.cl/wqlu2

Ley Orgánica de apoyo humanitario. [Organic Law on Humanitarian Support] Registro Oficial Suplemento 229 de 22-jun.-2020. https://n9.cl/8yi7

Organización Internacional del Trabajo. (2021). Derechos de los trabajadores. [Workers' rights]. Ginebra. Recuperado de: https://n9.cl/z1wii 